\title{
Copertencimento e coexistência para a efetivação da justiça espacial: um estudo de caso
}

\author{
Co-pertenencia y coexistencia para una eficaz justicia espacial: \\ un estudio de caso
}

Co-belonging and coexistence for the effective spatial justice: a
case study Lohaine Jardim Barbosa
lorijardim@gmail.com
Laburp - Laboratório de Estudos Urbanos e Regionais, da Paisagem e dos Territórios - Universidade
Federal Do Espirito Santo

Resumo: O presente artigo procura exercitar uma relação dialógica entre a linguagem literária de Arthur Rimbaud (aspectos subjetivos de apreensão do sistema-mundo) e a linguagem geográfica (conceitos - base de interpretação do sistema-mundo: espaço, lugar, território), enquanto postura política de experimentação de uma poética do espaço em prol de avançar em discussões epistemológicas na geografia. Busca-se trabalhar os conceitos de coexistência e copertencimento relacionados à percepção do conceito geográfico de lugar. As Residências Terapêuticas pensadas como um 'lugar' são analisadas a partir das relações que os pacientes estabelecem nos espaços da casa, em relação aos seus afazeres, sua rotina, suas relações sociais e interações, entre si e com a equipe que empreende seus cuidados.

Palavras-chave: Lugar. Diferença. Residências Terapêuticas. Políticas culturais.

Resumen: Este artículo trata de llegar a una relación satisfactoria entre el lenguaje literario de Arthur Rimbaud (aspectos subjetivos de la aprehensión del sistema mundial) y la lengua geográfica (conceptos - interpretación basada del sistema-mundo: espacio, lugar, territorio), mientras postura de política experimental de una poética del espacio para el beneficio de moverse en discusiones epistemológicas en la geografía. Tratase de trabajar los conceptos de coexistencia y co-pertenencia en relación con la percepción del concepto de lugar geográfico. Las Residencias Terapéuticas pensadas como un "lugar" se analizan a partir de las relaciones que los pacientes yacían en los espacios de la casa, en relación con su negocio, su rutina, sus relaciones sociales y las interacciones entre ellos y el equipo embarcado en su cuidado.

Palabras clave: Lugar. Diferencia. Residências Terapéuticas. Políticas culturáis.

Abstract: This paper aims to work out a satisfactory relationship between the literary language of Arthur Rimbaud (subjective aspects of apprehension of the world system) and geographic language (concepts - based interpretation of the world-system: space, place, territory), while experimental policy stance of a poetics of space for the advance in epistemological discussions in Geography. It seeks to analyze the concepts of coexistence and co-belonging in related to the perception of the geographical concept of place. The Therapeutic Residences thought of as a "place" are analyzed from the relationships that patients lay in the spaces of the house in relation to their business, 
their routine, their social relationships and interactions among themselves and the care staff.

Keywords: Place. Difference. Therapeutic Residences. Cultural Policies.

\section{INTRODUÇÃO}

Este artigo procura exercitar uma relação dialógica entre a linguagem literária de Arthur Rimbaud (aspectos subjetivos de apreensão do sistema-mundo) e a linguagem geográfica (conceitos - base de interpretação do sistema-mundo: espacialidades, desterritorialização), enquanto postura política de experimentação de uma poética do espaço em prol de avançar em discussões epistemológicas caras à geografia. Parte-se da poética do espaço de Arthur Rimbaud $(1994,2001)$ para discutir o conceito de coexistência e copertencimento propiciando novos olhares e possibilidades ao conceito de Justiça Espacial, propondo o deslocamento epistemológico deste a partir de uma ética e não de uma moral, tensionando assim, novos olhares que visem abarcar a diferença enquanto positividade.

Relata-se uma pesquisa de campo nas Retz (Residências Terapêuticas - casas utilizadas como moradia de ex-pacientes de hospitais psiquiátricos com objetivo de "reintrodução na sociedade") como forma de verificar a efetividade dos conceitos de copertencimento e coexistências com vistas à promoção da Justiça Espacial em condições de Justiça Social. Este trabalho efetivou-se por intermédio de visitas de campo, que ocorreram nas chamadas "Rodas de Conversas" efetuadas entre os técnicos do CAPs (Centro de Atenção Psicossocial) e as cuidadoras das RTs, de relatórios de visita de técnicos, relatórios de acompanhamento das RTs e também entrevistas com as profissionais do CAPs envolvidas diretamente na atenção e acompanhamento dos pacientes.

As RTs pensadas como um 'lugar' são analisadas a partir das relações que os pacientes estabelecem nos espaços da casa, em relação aos seus afazeres, sua rotina, suas relações sociais e interações, entre si e em relação à equipe que empreende seus cuidados.

Parte-se da premissa de que os conceitos de coexistência e copertencimento seriam fundamentais para a conquista da Justiça Espacial em condições de Justiça Social, e também tornam possíveis a revelação da importância da retomada da Cidade pelos sujeitos, a partir de sua apropriação e ocupação.

Segundo Lefebvre (1970), o direito à diferença é fundador dos demais direitos, e entre eles, é preciso situar o direito à Cidade e recolocá-lo como o direito que o cidadão morador da cidade tem de que suas diferenças sejam socialmente aceitas como legítimas. Isso não implica dizer que essas diferenças devam necessariamente agradar a todos, mas devem ser reconhecidas e toleradas. Dessa forma a diferença enquanto positividade está contida numa certa acepção de Lefebvre (2006), logo a coexistência e o copertencimento, para além de gerar 'tolerância', regeria convivência entre diferentes, em condições de igualdade que abarcassem a diferença enquanto positividade, com vistas à realização de uma justiça espacial, como propõe Soja (2009). 
Isso nos leva à necessidade de uma justiça espacial, tão amplamente debatido na Geografia Contemporânea, focada no direito e no respeito à diferença, que nos permita repolitizar a discussão sobre as desigualdades, estruturalmente crônicas no Brasil, e recuperar as práticas de solidariedade, conforme defende Brawley (2009). Isto nos leva a reflexão sobre como pensar políticas compensatórias capazes de resgatar a cidade como lugar de direito à manifestação da diferença; como garantir este direito sem que a diferença se torne causa de desigualdade.

Neste trabalho considerou-se necessidade do copertencimento e da coexistência enquanto elementos capazes de fornecer subsídios que direcionem os indivíduos à concreta promoção da justiça espacial e social. Nesse campo de estudo, desde a primeira visita à Residências Terapêuticas (RTs) foi evidente que a promoção do copertencimento e da coexistência em relação aos moradores das RTs e sua vizinhança, e desses entre si, influenciavam profundamente na percepção de lugar desses indivíduos, bem como na sua sensação de pertencimento e condição de autonomia. Ao comparar duas RTs, uma mais antiga e mista (misturada pacientes homens e mulheres) e outra mais recente (masculina), pode-se perceber os desafios impostos a promoção da autonomia desses sujeitos, bem como as dificuldades que a estrutura posta impõem à promoção do sentimento de pertencimento em relação à casa e à Cidade.

\section{O CAMPO: RESIDÊNCIAS TERAPÊUTICAS (RTS), O QUE SÃO?}

As Residências Terapêuticas (BRASIL, 2004; 2000b) são casas alugadas pelo poder público, atualmente administradas por ONGs, com o objetivo de garantir uma vida digna aos deficientes mentais, como defendido pela Luta Antimanicomial. Muitos foram os estudos que deram origem a militância pela desinstitucionalização dos hospitais psiquiátricos, no Brasil e fora dele, com destaque para a Itália (GOULART, 2007). No contexto capixaba essa militância envolveu diversos alunos e professores dos cursos de psicologia da Universidade Federal do Espirito Santo e de faculdades particulares (BARROS; BICHAFF, 2008; GOULART; DURÃES, 2010; AMARANTE, 1998, 1995).

A Lei 10.216 (BRASIL, 2001a) dispõe sobre um novo modelo assistencial de proteção e direito às pessoas portadoras de transtorno mental. Nessa linha, o Ministério da Saúde cria linhas específicas de financiamento para serviços substitutivos aos manicômios, como também gera mecanismos de fiscalização, gestão e redução programada de leitos psiquiátricos em todo o país. As ações do Governo Federal definem duas linhas de atuação: a construção de uma rede de atenção à saúde mental para substituir o modelo hospitalar e a fiscalização e redução progressiva e programada de leitos psiquiátricos (TENÓRIO, 2002). A rejeição ao modelo psiquiátrico hierarquizante e excludente e a busca por um modelo de atenção com base comunitária, resultaram na adoção dos Núcleos de Atenção Psicossocial e dos Centros de Atenção Psicossocial (CAPS) como serviços substitutos.

A atenção psicossocial, entendida como um novo paradigma para as práticas em saúde mental, apresenta-se segundo o discurso da Política de Saúde Mental vigente, 
capaz de substituir o modelo psiquiátrico dominante. Mas o que se observa no processo de implementação da Política de Saúde Mental no país, a partir da promulgação da Lei n. 10.216 (BRASIL, 2001a), é o aumento progressivo de uma cobertura assistencial em saúde mental extra-hospitalar, de base comunitária, mas que fornece serviços muito aquém do necessário. Esta não rompe com a estigmatização social existente sobre esses indivíduos, já que o direito do sujeito com transtorno mental, de ser tratado em serviço comunitário de saúde mental, com vistas à inserção na família, no trabalho e na comunidade (conforme estabelecido pela Lei), não é assegurado em sua integralidade. Isto porque a cobertura dos serviços existentes assevera tratamento apenas a cerca de metade da demanda da área (BRASIL, 2010).

Para além dos desafios institucionais impostos aos serviços de saúde pública e programas governamentais no que tange a efetivação dessa reforma psiquiátrica e a garantia de serviços públicos e direito à cidadania à pessoa com transtorno metal (AMARANTE, 1995; GOULART, 2006; MOREIRA, 2007), outros desafios nos impõem limites e dificuldades imensas na garantia da dignidade humana para esse público: a cultura e as relações sociais, que produzem injustiças espaciais e sociais.

Nesse sentido, o campo nessas RTs é extremamente frutífero para discutir os conceitos de coexistência e copertencimento, e o princípios da diferença bem como sua indissociabilidade em termos de reflexões que visem promover justiça espacial, social, cidadania e garantir a manutenção da dignidade humana.

Historicamente e socialmente excluídos da vida em sociedade, essas pessoas, sempre a margem do mundo produtivo, estão sujeitas à diversos tipos de injustiças e condensam em termos espaciais e relacionais um objeto rico de análise (MARCUSE, 2009). Ao explorar as relações intergrupais no contexto da convivência de duas residências terapêuticas, a partir das concepções dos habitantes do conjunto residencial onde estão localizadas, e também ao analisar a distribuição espacial dessas RTs, foi possível observar uma complexa rede de conceitos e significados que mediam a relação dos habitantes do conjunto residencial com as RTs, sendo essa relação composta por ambiguidades e contradições, e produção de injustiças. A vizinhança, às vezes favoráveis à inserção social dos moradores ao grupo social, outras vezes relatando a impossibilidade de uma ressocialização para esses indivíduos, torna fato a exclusão espacial e a criação das classificações em relação aos 'doidos', pondo em risco a identidade social positivamente avaliada dos moradores das RTs, conforme evidenciado por Ribeiro Neto (2014).

Assim, a coexistência aqui percebida como a aceitação e assimilação social dos moradores das RTs, não se efetiva, conforme observa Ribeiro Neto (2015, p.214):

A existência de certa aceitação social sobre os moradores das RTs, exemplificada pela participação na igreja local e em saídas desacompanhados de cuidadores em estabelecimentos comerciais da redondeza das RTs, pode ser um sinal favorável ao processo de inserção social, mas não significa sua inclusão plena como membros do grupo social, pois a interação entre habitantes e moradores das RTs aparentemente ainda se resume a breves encontros esporádicos, na maioria das vezes, na companhia de cuidadores. 
Entretanto, o estudo de Ribeiro Neto também aponta para possíveis mudanças nesses cenários ao evidenciar que a convivência dos vizinhos das RTs com os moradores dessas residências também auxiliou a desconstruir estereótipos sobre a loucura (agressividade, violência, descontrole), produzindo também condições de coexistência, embora não possamos falar em copertencimento ainda, nesses casos:

(...) mesmo com a tendência à separação das RTs observada neste estudo, existe um movimento que, com base na experiência concreta de vida com as RTs na vizinhança, aponta para a possibilidade da coexistência sem maiores conflitos entre os grupos envolvidos, ilustrando a ambiguidade das relações, uma vez que não tem fórmula de bolo para isso (RIBEIRO NETO, 2015, p. 215).

A importância do campo para as reflexões atuais é fundamental à partir de uma compreensão da justiça espacial enquanto prática, e visa promover reflexões epistemológicas alinhadas com a vida do vivido e os desafios cotidianos na conquista de uma real democracia, de direitos de cidadania e da efetivação das condições de dignidade humana.

Num mundo onde fragmenta-se o poder legítimo, e caem por terra as instituições que legitimavam o uso da força, novos personagens, jogos de força, rearranjos de poder, e modos de palavra se fazem circular, novas sensibilidade e inteligibilidades são postas em movimento. Novas injustiças são produzidas e engendram mecanismos de dominação, subjugo e impedem a realização da cidadania e a promoção de condições de dignidade da pessoa humana. Coloca-se assim, novos desafios à promoção da justiça espacial. Sendo assim a:

la justice spatiale devient alors une pratique qui consiste à forger des sujets qui résistent à la logique d'entreprise, refusent l'autoritarisme moral et re-politisent les inégalités sociales" em que o real trabalho da justiça espacial passa por "consisterait donc à ouvrir ces institutions à la responsabilité et à la prise de décision démocratiques, autant qu'à forger de nouveaux modes de prestations sociales qui puissent efficacement rivaliser avec la mainmise du capital financier sur la vie urbaine de tous les jours (BRAWLEY, 2009, p. 13-14).

Seu desafio compreende resistir à lógica dos negócios, e do capital global, repolitizar as desigualdades sociais, e promover agendas coletivas em prol do bem estar social e individual, o que passa pela necessidade de se compreender a forma como as maneiras e modos de existência e de organização do sensível se constituem e se movimentam na atualidade. Ou seja, que perpassam uma partilha do sensível.

\section{A BUSCA: JUSTIÇA ESPACIAL}

A justiça espacial é uma prática e deve se constituir enquanto prática que rasura a lógica dominante, produzindo linhas de fuga capazes de desestabilizar a lógica neoliberal capitalista. Reconstruir a ideia de espaço público enquanto copertencimento é necessário para escapar à lógica perversa da dupla neoliberalismo e neoconservadorismo de que 
fala Brawley (2009). Somente dessa forma é possível superar a segregação socioespacial à qual a população com transtornos mentais se encontra sujeita, mesmo após anos de luta social pela desinstitucionalização dos Hospitais Psiquiátricos. Somente remoldando nossas relações sociais, e a forma como nos constituímos em inter-relação uns com os outros, o direito à cidade deixará de ser um direito a viver na cidade para ser um direito de constituir coletivamente as cidades, tendo a diferença como positividade.

Bernard Bret, ao discutir a Teoria da Justiça de John Rawls (2002), discute o clássico binômio universalidade e particular buscando uma conjugação para essa questão, sem cair num universalismo autoritário ou numa renúncia da autonomia moral e da própria razão:

Le refus de l'universel conduit à une impasse: considérer la philosophie morale et politique, dès lors qu'elle proclame l'universalisme de certaines valeurs, comme une vaine spéculation intellectuelle sans prise avec le réel (...)L'alternative réside-t-elle dans le refus assumé de l'universel et l'affirmation des particularismes moraux. On tombe alors dans le danger du relativisme et, partant, du communautarisme. Enoncer en effet une éthique qui serait particulière à un groupe, c'est reconnaître une autorité normative à des pratiques sociales spécifiques (BRET, 2009, p. 2).

Para Bret, a diversidade exigiria uma teoria universal, mas que passe pelos princípios da diferença e da igualdade, como defendido na Teoria da Justiça de Rawls. Segundo Bret, Ralws resolveria à partir de uma boa saída a questão da legitimidade do universal, num mundo onde se impera a diversidade, e isso se deveria a sua perspectiva de 'justiça'. O princípio de Rawls, ou priorizar o princípio da igualdade e da diferença:

Ce qui fait l'universalité desprincipes rawlsiens, c'est le voile d'ignorance mis par le sujet entre le monde réel et lui, de façon que soit imaginée une position originelle où il pourra rationnellement énoncer les règles de vie équitables pour les partenaires sociaux, c'est-à-dire les règles qui répartiront au mieux les avantages et les charges de la coopération sociale. On sait que, pour John Rawls, la repartition des biens matériels et immatériels la meilleure est celle qui sert le mieux les partenaires sociaux les plus modestes (maximiser le sort de ceux qui ont le minimum : principe du maximin). On sait aussi qu'il ne pose pas a priori que l'égalitarisme (l'égalité de tous dans tous les domaines de la vie sociale) serait nécessairement la configuration la plus efficace pour atteindre cet objectif. On sait enfin qu'il donne la priorité au principe d'égalité sur le principe du maximin, pour ce qui regarde la valeur intrinsèque des personnes et leurs droits. Le système rawlsien articule donc et hiérarchise son principe d'égalité et son principe de difference (BRET, 2009, p.4).

Baseando sua ideia de justiça na razão e na ideia de um homem racional, que partilha os valores de uma comunidade, ou seja, uma cultura e um bem comum, Bret aponta que em Rawls (2003), o confronto do indivíduo com o universal resultaria no controle do cumprimento da moral e da ordem da lei. Ou seja, o social particular das comunidades seriam legítimos apenas na condição da não violação dos valores universais de uma comunidade, e esse universal garantiria a própria existência da comunidade humana. Seu 
debate abriria o diálogo para se discutir o bem comum e o debate público, e para a distinção entre o bom e o justo:

En d'autres termes, comprendre le monde et transformer le monde sont les deux facettes de la philosophie rawlsienne. Puisque John Rawls distingue le bien et le juste en définissant le bien comme ce qu'un être rationnel peut souhaiter et le juste comme ce qui est conforme à des principes de justice eux-mêmes énoncés au terme d'une procédure rationnelle, il apparaît logique de considérer le juste comme un bien puisque le juste donne une satisfaction qui, elle, est un bien (BRET, 2009, p.6).

A Teoria da Justiça de Rawls coloca a necessidade de se conhecer o mundo para agir no mundo, e nos coloca a variedade de percepções, e interpretações sobre o que pode ser o 'justo' em sociedades e culturas diferentes, por isso, propõem um diálogo de civilizações na busca de consensos e convergências:

Sur les actions à entreprendre, le dialogue des civilisations est sans doute la méthode la plus crédible, parce que les principes de justice peuvent se décliner de façons multiples dans les différentes aires culturelles et parce que considérer les partenaires sociaux comme des êtres rationnels conduit logiquement à les considérer comme susceptibles de trouver des consensus de recoupement validant des convergences entre les positions initiales (BRET, 2009, p.6).

Nesse sentido, Bret irá apontar que considerar o objeto da Geografia (diferenciações espaciais) e a Teoria de Justiça de Rawls, poderia ajudar a compreender as injustiças espaciais não como um acidente no processo, mas sim como processo de produção de desigualdades espaciais. Auxiliando assim, na própria compreensão sobre desigualdades espaciais como direito, e na defesa da positividade da diferença:

Pour la géographie, dans la mesure où elle s'occupe des différenciations spatiales (c'est un savoir), et pour l'aménagement, dans la mesure où il a pour objet de transformer le territoire en fonction d'un projet de société (c'est une politique), la Théorie de la Justice constitue un fondement théorique extrêmement fécond. Contrairement à certaines objections qui lui ont été faites, elle permet d'appréhender la diversité du réel, et d'abord les inégalités des niveaux de développement (BRET, 2009, p.7).

A Teoria da Justiça traria respostas ao permitir o estabelecimento de relações entre a diversidade cultural e a ação para a promoção de uma justiça. Embora a aplicação de seus conceitos seja extremamente difícil, essa pode nos auxiliar a garantir que o princípio de realidade não supere os princípios de justiça, tendo sempre em mente que o princípio de justiça deve ser objeto de reflexão e de revisão a todo o momento, e que este deve advir de um conhecimento sobre as comunidades, sua cultura, seus valores e a busca de um consenso social, sobre o bom e o justo.

Para uma perspectiva crítica na análise do espaço, um conceito espacial especifico de justiça pode trazer importantes contribuições para o debate. Este conceito de justiça espacial, apesar de retomado muito recentemente, já esteve presente nos escritos de Henri 
Lefebvre (1991, 2008) e outros geógrafos, principalmente no que diz respeito às teorias sobre justiça e direitos humanos relacionadas ao direto à cidade.

As revisões atuais ao conceito de espaço, que não é lido mais como um receptáculo da atividade humana, mas sim como possuidor de potencial político e como uma produção aberta e múltipla, onde "o espaço jamais poderá ser essa simultaneidade completa, na qual todas as interconexões já tenham sido estabelecidas e no qual todos os lugares já estão ligados a todos os outros" (MASSEY, 2008, p.32), produziu novos olhares sobre a causalidade espacial urbana. E atualmente, como aponta Soja $(2009$, p.2) a crítica espacial contemporânea aponta três princípios básicos fundamentais para se pensar o espaço na atualidade:

a) celui de la spatialité ontologique des êtres humains (nous sommes tous des êtres spatialement tout autant que socialement et historiquement situés). b) celui de la production sociale de la spatialité (l'espace est produit socialement et peut du coup être transformé socialement). c) celui de la dialectique socio-spatiale (le spatial est socialement produit et donc la réciproque est aussi vraie).

As justiças e as injustiças são realizadas e constituídas espacialmente, são multiescalares e precisam assim ser pensadas. O termos 'justiça espacial' aqui trabalhado enfatiza intencionalmente os aspectos espaciais e geográficos da justiça e da injustiça, considerando enquanto justo a distribuição equitativa de bens, oportunidades, recursos socialmente valorizados, conhecimento, tecnologias, e oportunidades, adotando-se como princípio a positividade da diferença.

Como aponta Soja (2009) o termo justiça espacial não vem substituir a justiça social, econômica ou territorial, mas se constitui enquanto uma forma de olhar para a justiça, uma escolha teórica e política, que visa a elaboração de reflexões críticas a partir de uma perspectiva espacial. A adoção da dimensão espacial à ideia de justiça visa reconhecer também, que as geografias que produzimos e vivemos podem ser libertadoras, opressoras, justas ou injustas e ter efeitos positivos ou negativos sobre quase tudo o que se faz:

La justice (ou l'injustice) spatiale peut être comprise à la fois comme une conséquence et comme un processus, en tant que géographies ou schémas de répartitions qui sont en eux-mêmes justes ou injustes, et en tant que processus qui produisent ces résultats. $S$ 'il est relativement facile de trouver des exemples d'injustice spatiale, il est beaucoup plus difficile d'identifier et de comprendre les causes sous-jacentes qui produisent les géographies de l'injustice (SOJA, 2009, p. 3).

Nesse sentido, no estudo de caso proposto, essa perspectiva auxilia a identificação das discriminações relacionadas aos espaços e às relações, que resultam do tratamento desigual que alguns segmentos da população sofrem, histórica e culturalmente, no caso indivíduos que sofrem de transtornos mentais graves. Essas discriminações, embora não se reduzam à segregação espacial, trazem a necessidade de reflexão sobre a organização política dos espaços a partir de uma perspectiva da promoção de justiça espacial, uma vez que essa organização é fonte de injustiças que vão muito além de um apartheid territorial. 
Les discriminations liées aux localisations (discriminations localisationnelles), résultat du traitement inégal fait à certaines catégories de population en raison de leur localisation géographique, s'avèrent fondamentales dans la production d'injustice spatiale et dans la création de structures spatiales pérennes, fondées sur privilèges et avantages. Les trois forces les plus connues qui agissent pour produire de la discrimination localisationnelle et spatiale sont la classe sociale, la race et le genre, mais leurs effets ne doivent pas être réduits à la seule segregation (SOJA, 2009, p.3).

Por isso, defendendo enquanto princípio o entendimento da diferença a partir de sua positividade, por um conceito de justiça espacial que seja capaz de relacionar o global e o local, defende-se a ideia de que a coexistência e o copertencimento são conceitos fundamentais nas reflexões acerca das justiças e injustiças espaciais. Estas estão inscritas na espacialidade e não podem ser indissociadas de geografias multiescalares que revelem os processos que cimentam estruturas duradouras de privilégios e desigualdades. Pensar em igualdade socioespacial é fundamental para a promoção de políticas culturais sensíveis à diferença e a manutenção da dignidade humana e da equidade social.

\section{A INTER-RELAÇÃO: O CONCEITO DE LUGAR}

O conceito espacial de 'lugar' foi amplamente discutido por diversos geógrafos, e sua utilização para expressar um sentido locacional de um determinado espaço delimitado fez com que este conceito fosse relegado à plano secundário em relações a outros conceitos espaciais como espaço, território e paisagem. Atualmente 'lugar' é considerado um conceito fundamental para a Geografia graças a Yi-Fu Tuan, percursor do movimento humanista na Geografia, cuja teoria procura compreender as dimensões do viver humano e o papel fundamental da cultura em suas elaborações.

Tuan, a partir de sua perspectiva geográfica, não pretende elaborar uma Ciência da Terra, e sim, uma ciência entrosada com as Humanidades e Ciências Sociais "... no sentido de que todas compartilham a esperança de prover uma visão precisa do mundo humano" (TUAN, 1982, p.143). Dessa forma, os conceitos tuanianos buscam questionar papel da cultura, e das relações culturais nas dinâmicas sociais e humanas, alinhando sua reflexão inexoravelmente às dimensões práticas do viver humano.

Em Topofilia (de 1974, editado no Brasil em 1980), Tuan destaca as ligações afetivas evocadas pelo ambiente que transformariam um espaço em lugar, ou seja, os sentimentos sobre o lugar (sense of place) e as relações entre a cultura e o ambiente natural que definiriam o que este lugar simboliza em termos culturais e afetivos. Já na obra Espaço e Lugar (1983), este procura teorizar sobre o pensar e o sentir o espaço, que seriam atos da experiência humana. $\mathrm{O}$ autor demonstra como as experiências cotidianas constituiriam as perspectivas existenciais e também epistemológicas, segundo as quais o homem percebe o espaço e o assimila enquanto 'lugar'. Tuan reforça a existência de uma relação dialética entre o homem e o lugar, constituindo-se este enquanto uma construção puramente humana, uma vez que a experiência do homem no espaço-ambiente (objeto) se revelaria na constituição 
do lugar (sujeito), e como os significados dessa ligação conduziriam as ações humanas e a forma como o homem simboliza a sua existência. Tuan aponta como a natureza do lugar variaria de acordo com a experiência ambiental, os mitos humanos, e suas relações sociais, culturais e históricas.

[ ]... cultura diferencia o homem dos outros animais. Isto é particularmente verdade na esfera moral. Assim como só os seres humanos possuem linguagem, no sentido amplo da palavra, então eles - e só eles - possuem um senso inato de -bem e mal-, -certo e errado (TUAN, 2008, p.193-94, tradução nossa).

O lugar aqui pensado assenta-se sobre a ideia do lugar vivido, o lugar da construção das experiências humanas. É um lugar que remete à sentimentos, à sensação de pertencimento, do conhecido, e onde a partir da relação homem e espaço que o cerca, é possível se apropriar desse espaço imediatamente circundante para assim se produzir e reproduzir a vida. O lugar, enquanto um espaço dotado de valor.

O lugar pode adquirir profundo significado para o adulto através do contínuo acréscimo de sentido ao longo dos anos. Cada peça dos móveis herdados, ou mesmo uma mancha na parede, conta uma história (TUAN, 1983, p. 37).

Ou seja, o lugar é o espaço da experiência humana dotado de sentido e significado que lhe foi atribuído ao longo do tempo, pelos sujeitos, que significam, constroem e vivenciam esses espaços. Por isso, pela experiência e no estabelecimento de relações sociais com o ambiente, os homens nomeiam os 'lugares' - são lugares de memória, lembrança, sentimentos, cheiros, que remetem a sensações, percepções e principalmente ideias, que significam seus espaços.

Essa porção espacial dotada de sentimento também nos é dada e algumas vezes impostas pelas limitações espaciais a nós embutidas: limitações de convivência social, de informação, de circulação, e muitas outras. Nossos corpos são também limitados à certas experiências em virtude de imposições sociais, políticas, e espaciais - se eu numa fui à praia, não terei a ideia sobre o que ela é, nem uma imagem que a represente. Ou seja, a praia para mim não é um lugar, é só uma 'coisa'. Essa limitação vai definir nossa relação com os espaços sociais bem como nosso lugar social.

Para este artigo, o lugar deve ser relacionado às suas imbricações espaciais e sociais inerentes, e as relações de poder que engendram o enquadramento dessas definições. Para as discussões aqui pretendidas nos interessa o 'lugar' da loucura, enquanto um lugar social onde se coloca e se encerra (ou limita) o louco, bem como o lugar das relações: casa, cidade, vizinhança, onde é permitida sua circulação. Trabalha-se o lugar simbólico, e o lugar enquanto espaço de interação e significação do mundo.

\section{O LUGAR DO LOUCO}

O que vem a ser a loucura? Talvez deva-se pensa-la como atribuição e não como um conceito, pois ela não pode ser tomada como uma instância universal. A própria história 
da palavra não se refere a um fenômeno único que se repete ou evolui, mas a uma multiplicidade de fenômenos. Loucura é simplesmente uma palavra usada para classificar, enquadrar e encerrar o outro! No entanto, não se está livre das palavras, de seu peso, de suas amarras e nem da capacidade que nelas depositamos de produzir categorias, ideias, valores e semelhanças.

Ao pensar numa historicização dessa palavra, tenta-se remontar à sua origem e caminho percorrido. Encontra-se muitos nomes da loucura em tempos e espaços diversos - o louco surgindo em cena a partir de diversas máscaras, performances e surgindo em diferentes palcos e cenários. Conforme destaca Veyne (1992, p. 144) “A loucura não existe: só existe sua relação com o resto do mundo". Não se pode falar da loucura como um objeto específico, como um fato. A loucura é mais relacional que constituinte, ou constitutiva; nasce das relações que as pessoas estabelecem umas com as outras e se institucionaliza. Para Foucault, reconstruindo a história da loucura, esta se inicia a partir do desaparecimento dos leprosários na Idade Média na Europa, com seus ritos de segregação destinados não à suprimir a lepra, “(...) mas sim a mantê-la a uma distância sacramentada, a fixá-la numa exaltação universal" (FOUCAULT, 1997, p. 5). A loucura se constitui a partir de práticas de exclusão e segregação, que mais tarde assumiriam também outras formas de segregação espacial incluindo pobres, vagabundos, presidiários, órfãos e crianças abandonadas. O fenômeno da loucura apareceu no século XVII, antes de ser apropriado pela medicina, como herança da lepra e do movimento de segregação desses doentes. A loucura herda a produção de um espaço isolado e afastado da vida que acontecia nas cidades, e que coloca os indivíduos na posição de menos humanos, ou não humanos:

[...] a loucura é arrancada a essa liberdade imaginária que a fazia florescer ainda nos céus da Renascença. Não há muito tempo, ela se debatia em plena luz do dia: é o Rei Lear, era Dom Quixote. Mas em menos de meio século ela se viu reclusa e, na fortaleza do internamento, ligada à Razão, às regras da moral e a suas noites monótonas (FOUCAULT, 1997, p. 78.)

Antes da segregação dos 'loucos', os chamados 'alienados' se faziam notar na paisagem da Europa, errantes pelas cidades, de um porto a outro, expulsos das cidades e entregues à própria sorte no mar. Mas eram livres, como destaca Foucault (1997, p. 12), o louco: “É um prisioneiro no meio da mais livre, da mais aberta das estradas: solidamente acorrentado à infinita encruzilhada. É o Passageiro por excelência, isto é, o prisioneiro da passagem".

$\mathrm{Na}$ atualidade talvez não tenha havido mudanças, resgatando no pensamento de Foucault a figura do 'errante', expulso da cidade, do louco de nossas cidades. A loucura está sempre colocada como o 'não desejado' da paisagem das grandes cidades, como um 'fora', e ou 'não parte'. No século XVIII, Foucault identifica que:

Doentes venéreos, devassos, dissipadores, homossexuais, blasfemadores, alquimistas, libertinos: toda uma população matizada se vê repentinamente, na segunda metade do século XVIII, rejeitada para além de uma linha de divisão, e reclusa em asilos que se tornarão, em um ou dois séculos, os campos fechados da loucura (FOUCAULT, 1997, p. 102.) 
Nossos loucos foram por anos, após a medicina se apropriar e se responsabilizar pela' gestão da loucura', trancafiados em hospitais psiquiátricos, muitos, durante toda a sua vida (ARBEX, 2013). Em Doença mental e psicologia (1991) Foucault situa historicamente a constituição do conceito de doença mental, que de acordo com o autor está relacionado a uma série de práticas médicas, que justificaram a própria definição de campo da psiquiatria, e onde doença e tratamento se situam historicamente e marcam a apropriação da loucura pela medicina:

[...] organização da rede médica, sistema de detecção e profilaxia, forma da assistência, distribuição de cuidados, critérios de cura, definição da incapacidade civil do doente e da sua irresponsabilidade penal; em resumo, todo um conjunto que define numa cultura dada a vida concreta do louco (FOUCAULT, 1991, p. 90).

A psiquiatria nasce para administrar e gerir a loucura, uma vez que ao final da Revolução Francesa, o louco adquire status de alienado e permite à medicina definir a medicalização e tutela desses sujeitos à psiquiatria. Servindo aos interesses do governo francês, preocupado em extirpar da paisagem das cidades francesas os chamados 'alienados', os homens da desrazão, que tanto ameaçavam o Pacto Social, definido a partir de um contrato entre homens livres e racionais. Ao passar a responsabilidade dos loucos aos médicos, a loucura se torna um problema técnico mental, uma doença, sendo assim; administrável (CASTEL, 1978). A psiquiatria e seu discurso moralizante irá legitimar uma prática de segregação social e espacial de indivíduos que seriam por ela classificados como loucos.

[...] a Psiquiatria torna-se um poder que se exercerá como regulação moral das individualidades, definindo valores que estabelecerão o campo de variação do comportamento humano. Este será considerado como mórbido ou sadio, numa escala estabelecida pela razão psiquiátrica (BIRMAN, 1987, p.12).

A medicina, ao se tornar vetor desse processo, se firma no espaço social como instância preocupada com a gestão da saúde coletiva e controle das epidemias, e enquanto agentes promotores da saúde e da normalidade do todo social. Dessa forma, a invenção da loucura é também a invenção de um patológico que justificou uma segregação espacial para uma certa parcela da população, que ao longo dos tempos não foi definida única e exclusivamente pela loucura, mas sim, por uma necessidade do Estado de administrar aquilo que não deveria fazer parte da paisagem da cidade - os indivíduos que incomodavam o todo social de uma determinada comunidade, e que por serem diferentes, incomodavam a ordem social. Como nos aponta Canguilhen (2009, p. 200-201):

(...) o que caracteriza um objeto ou um fato dito normal, em referência a uma norma externa ou imanente, é poder ser, por sua vez, tomado como ponto de referência em relação a objetos ou fatos ainda à espera de serem classificados como tais. Portanto, o normal é, ao mesmo tempo, a extensão e a exibição da norma. [...] Ele requer, portanto, fora de si, a seu lado e junto de si, tudo aquilo que lhe escapa. Uma norma tira seu sentido, sua função e seu valor do fato de existir, fora dela, algo que não corresponde à exigência que ela obedece. 
O novo lugar da loucura esteve intimamente articulado ao surgimento da Sociedade Industrial e uma nova moral nascente (NIETZSCHE, 2009), que exigia um novo modelo de ser humano, habilitado a produzir mais valia e voltado para a condução de sua sociedade ao progresso. A Medicina Mental surge então como uma nova instituição social e como um discurso científico, em um momento de reorganização sociomoral do sujeito (BIRMAN, 1987).

Os loucos, ou 'anormais' não escapam apenas ao que é definido como normal, escapam à própria lógica que funda o social. Na verdade, o problema está nesta própria lógica, incapaz de abarcar a diferença, justamente por partir de uma moral e não de uma ética. Afinal:

'Normar', normalizar é impor uma exigência a uma existência, a um dado, cuja variedade e disparidade se apresentam, em relação à exigência, como um indeterminado hostil, mas ainda que estranho. Conceito polêmico, realmente, esse conceito que qualifica negativamente o setor do dado que não cabe na sua extensão embora dependa de sua compreensão (CANGUILHEN, 2009, p.201).

A loucura, constituída a partir do monopólico do saber da Medicina Mental, se tornou patologia e justificou sem problemas, em diversas sociedades, o encarceramento de indivíduos. Embora o movimento de desinstitucionalização dos hospitais psiquiátricos tenha sido uma grande vitória, ela não retirou da psiquiatria esse monopólio, nem muito menos operou uma mudança significativa em termos das práticas sociais que encerram esses sujeitos na condição de 'não normais'.

Tanto a medicalização da loucura, como também a medicalização do crime ${ }^{1}$, a exemplo das medições de crânios e expressões faciais que denunciariam tendências a psicopatia, são movimentos da ciência médica na busca de apreender uma verdade que ultrapasse a verdade do corpo mas, ainda assim, esteja intimamente ligada a ele.

À psiquiatria nascente interessavam os comportamentos desviantes, bem como a aparência, as formas e os traços daqueles que praticavam tais comportamentos. Era desse modo que justificavam o racismo, as diferenças entre as classes sociais, a superioridade do homem sobre a mulher, bem como também a tendência a cometer crimes, entre outras invenções. Esses e outros discursos que se revestiam, e revestam ainda hoje, sobre o manto de serem "cientificamente comprovados" reforçam a crença na supremacia do biológico em detrimento do social. Antes de serem teorias biológicas, são discursos moralizante que produzem práticas discriminatórias.

No Brasil, é na virada do século XX que começam a surgir os locais de internação dos chamados 'loucos'. Até o final do século XIX, o controle da loucura caracterizava-se como simples mecanismo de exclusão social, voltado para os loucos considerados perigosos. O alienismo, nascido na Europa ao final do século XVIII, surge no Brasil apenas um

1 Cunha fala sobre como a medicalização da loucura não deixa de ser uma medicalização do social: uma fala que elabora, cientificiza procedimentos discriminatórios e excludentes para, medicalizando aquilo que é estranho', oferecer uma alternativa política e moralmente aceitável para famílias atingidas pela desgraça e pela vergonha, para governos embaraçados pela necessidade de dispor de saídas institucionais de exclusão e controle (CUNHA, 1986, p. 160). 
século depois e com características bem diversas da europeia (CUNHA, 1986). Embora as técnicas da psiquiatria europeia tenha influenciado fortemente a formação dos psiquiatras brasileiros, as internações, bem como as definições de tratamento no Brasil, responderam às condições sociais e históricas particulares. Cunha (1986) destaca que, no Estado de São Paulo, a internação dos indivíduos em Asilos (como eram denominados os Hospitais Psiquiátricos) ocorre com o objetivo de controlar os males causados pela explosão do crescimento urbano ao final do século XIX. As parcelas consideradas improdutivas, como os idosos, as crianças abandonadas, deficientes físicos e pessoas com transtornos mentais, eram internados nesses mesmos Asilos. Esses indivíduos inaptos ao trabalho e à vida considerada produtiva, se tornavam um problema para o Estado, e não mais para os grupos sociais e seus familiares:

Setores improdutivos, como a velhice, os "menores", certo tipo de doentes, débeis mentais, deficientes de diversas qualidades terão reinventado o seu lugar. Na cidade, eles tenderão a deixar de ser uma questão que afeta ao grupo familiar ou social mais diretamente concernido, para constituírem problema efetivo para a administração pública. Alguns desses setores encontrarão no hospício, ao lado dos loucos, o seu definitivo "lugar de repouso" (CUNHA, 1986, p. 31).

A loucura sempre foi, portanto, uma questão moral e social, antes e depois de se tornar médica e biológica. Mesmo depois da reforma psiquiátrica que levou o mundo a pensar que a loucura habita principalmente em todos nós (ARBEX, 2013; AMARANTE, 1998, 1996), as práticas de segregação e separação entre 'normais' e 'anormais' ou 'não-normais' persistem, bem como assistimos a técnicas de produção de segregações veladas, e a reprodução do encerramento do outro a partir de nossos manicômios mentais ${ }^{2}$.

\section{O CAMPO: A EXPERIÊNCIA NAS RTS E O LUGAR DA CASA}

O campo de estudo partiu do Centro de Atenção Psicossocial - CAPS Cidade, localizado no CRE Metropolitano (Centro Regional de Especialidades), localizado no município de Cariacica ES. As duas RTs, localizadas em dois bairros do município de Cariacica, foram escolhidas em virtude de possuírem dinâmicas bastante distintas e por representarem dois momentos da instalação das RTs. A mais antiga é a única a experimentar o formato de residência mista (lá habitam homens e mulheres) e a outra, por ser a mais recente, e ter recebido os últimos pacientes que ainda estavam internados no HEAC (Hospital Estadual de Atenção Clinica) estão os pacientes mais regredidos e com maior dificuldades de

2 Aqui remete-se ao conceito de Peter Pelbart (1989) aos nossos próprios preconceitos em relação as pessoas com transtornos mentais e a convivência com essas pessoas. O autor defende nosso direito à "desrazão": "[...] seria necessário acrescentar imediatamente: um direito à desrazão, mas sem confiná-la àquele cantinho privado e secreto de nosso psiquismo chamado "nossas fantasias", onde ela costuma dormitar inofensiva. O direito à desrazão significa poder pensar loucamente, significa poder levar o delírio à praça pública, significa fazer do Acaso um campo de invenção efetiva, significa liberar a subjetividade das amarras da Verdade, chame-se ela identidade ou estrutura, significa devolver um direito de cidadania pública ao invisível, ao indizível e até mesmo, por que não, ao impensável. Libertar-se do manicômio mental é isso tudo e muito mais. No entanto, para que a "libertação" da desrazão não venha a ser mais uma astúcia da Razão - como talvez o seja a libertação dos loucos - é preciso evitar suas ciladas, que não são poucas" (PELBART, 1989, p.107). 
interação. Os pacientes em sua maioria, não tinham autonomia, muitas vezes, nem mesmo para se vestir sozinho, ou utilizar o banheiro sem o risco de comerem suas próprias fezes (comportamento este comum no caso de um dos pacientes dessa Residência).

Essas diferenças foram cruciais para a análise dos elementos pretendidos e, apesar de localizada, a análise de campo tornou possível reflexões a serem consideradas também em níveis macrossociais.

O campo, de inspiração etnográfica, foi acompanhado por uma psicóloga e uma terapeuta ocupacional da CAPS - Cidade. Os técnicos do CAPS estavam efetuando passando por mudanças profundas no relacionamento entre a instituição e a ONG responsável pela administração das RTs e nesse sentido, puderam ser acompanhadas as visitas denominadas: "Rodas de Conversa", onde os técnicos na CAPS quinzenalmente ouviam as queixas, desabafos, dificuldades e o dia a dia dos cuidadores que atuavam nas duas RTs sob responsabilidade do CAPS Cidade.

Durante essas visitas foi possível perceber o real isolamento dessas residências em relação à vizinhança na qual estão inseridas, e como a falta dessa convivência contribui para a manutenção de uma situação de dependência do modelo institucional do manicômio e do silenciamento dos sujeitos.

A proposta inicial de trabalhar com oficinas de desenho, solicitando aos mesmos que desenhassem sua casa, não foi possível devido a impossibilidade deles significarem a palavra casa. Dessa forma, o contato com as cuidadoras foi bastante revelador da situação desses sujeitos, bem como dos desafios institucionais da desinstitucionalização dos manicômios, já que a percepção inicial era de que se tratava de mini manicômios, mas sem os cuidados médicos. Com o tempo de campo, a RT foi se tornando mais 'casa', e a proximidade com as cuidadoras e os pacientes fez com que a reação inicial se dissolvesse e surgisse a compreensão de que, em algum sentido, as RTs seriam casas. Mesmo que ainda encerrassem de alguma forma os sujeitos no isolamento e no silenciamento do manicômio, as relações afetivas que as cuidadoras e os residentes desenvolviam, na maioria dos casos, permitia chamar aquele lugar, pelo menos, de residência.

Num segundo momento foram realizadas entrevistas com as técnicas responsáveis pelas RTs, e também com atores envolvidos nas instalações dessas Residências no município de Cariacica A partir de suas falas, e das indicações de entrevistas com outros técnicos, foi reconstruído um histórico das lutas e dificuldades do processo. As atas dos acompanhamento e os relatórios de gestão foram fundamentais para levantar a dificuldade de se efetivar condições de coexistência e copertencimento em relação aos pacientes e aos espaços da cidade, e mesmo desses em relação a Residência.

\section{CADERNO DE CAMPO: A EXPERIÊNCIA EM SI}

O primeiro contato foi esclarecedor do meu campo: nada seria como o planejado, e tudo fugiria da estratégia elaborada. Tanto os moradores das RTs apresentavam diferentes 
estágios de interação e níveis de transtorno mental, como as minhas estratégias para me aproximar e me relacionar com eles deveria ser diferenciada.

As conversas com as cuidadoras eram sempre muito demoradas, pois elas desabafavam desde seus problemas pessoais, problemas com a empresa, dificuldade com os colegas de trabalho, conflitos com outros cuidadores e muito mais. Estressadas com os cuidados com a casa e os residentes, elas ainda tinham que se virar sem estrutura, limpar a casa e banheiros sem equipamento de proteção, e sem como se proteger de alguma reação de algum residente mais exaltado. Todas relataram ter passado por momentos de tensão, inclusive agressão, mas demostraram entender serem estes casos fatos isolados e específicos de pacientes mais violentos.

Em sua maioria, as cuidadoras relatavam carinho pelos residentes e que, mesmo em situações de atraso de salário, não teriam coragem de deixá-los sozinhos, já que dependiam delas. A relação afetiva e a forma como "conheciam pessoalmente" cada um, levantou a percepção de que, apesar das dificuldades, a relação dentro da RT era de cuidado. Com relação à vizinhança, "É como se não existíssemos. Não existe relação, nem bom dia eles nos dão. É elas lá e nós aqui. Acho que eles tem medo, e mesmo com a gente que trabalha, eles não dão bem bom dia e boa tarde".

Sem possuir qualquer relação com a vizinhança, também os pacientes não tinham o costume de sair. Durante a conversa foram relatados episódios assados de internos com transtornos sexuais, que foram contornados com medicação. Durante as visitas à residência mais antiga, um rapaz mais jovem tentava sempre apalpar a terapeuta ocupacional, sendo sempre repreendido por ela. Ele fazia o mesmo com as cuidadoras, o que era perfeitamente compreensível, por se tratar me um rapaz jovem, internado ainda adolescente, e sem muito contato com mulheres além das cuidadoras. Sobre passear com eles, as cuidadoras afirmaram ser impossível, com a exceção um residente mais autônomo (com transtorno mental menos grave). Por serem apenas duas para todos os cuidados da casa, jamais teriam condições de levar os pacientes para um passeio, e relataram sentir muito o isolamento dos residentes: "Pois é, tadinhos, eles ficam trancados aqui, não saem, deve ser muito ruim, muito mesmo. Eles ficam presos, e seria bom se pudéssemos sair com eles, eles passearem interagirem com as pessoas, eu penso que seria bom". Esta sensação de isolamento dos residentes era fato consumado para as cuidadoras, que relataram que o contato "com outras pessoas" faria muito bem para os pacientes, para interagirem mais, falarem mais, e não se sentirem "presos". As cuidadoras da residência mais nova não tiveram problemas em confirmar que os moradores não saem

Em uma das visitas, uma cuidadora substituta veio de outra RT. A conversa com a mesma foi muito interessante, tanto por fornecer dados sobre a rotina em outras residências, quanto pelo perfil das RTs. Dada sua experiência em residência onde os sujeitos seriam mais autônomos, a mesma afirmava que naquela RT em questão havia cuidados excessivos que não permitiriam aos moradores mais autonomia: "Aqui eles ganham tudo nas mãos, são tratados como criança. É tudo nas mãos, eles não participam das tarefas. Eu não estou acostumada com isso, e para eles é ruim, ficam o dia todo sem fazer nada, andando na varanda! Eles tem que ter tarefa, mesmo que depois tenhamos que ir atrás e fazer tudo novamente, mas eles tem que começar 
a apreender. Nas outras funciona, aqui também tem que ter". A mesma informou que existia a cultura das cuidadoras em infantilizar os moradores, a não promover sua autonomia na casa, agravando a situação dos moradores. Seria uma forma de manter maior controle. De fato, a cultura nesta RT visava à manutenção da relação hospitalar, motivo pelo qual os moradores insistiam em chamar as cuidadoras de "enfermeiras". É muito comum nas falas a expressão "tadinhos" e outros termos diminutivos e desqualificadores do indivíduos, que os encerram numa posição de coitados e vítimas, retirando-os da posição de sujeitos. Elas relatavam que não haviam passeios e outras forma de socialização fora da casa. E muitas vezes, durante as visitas se via os residentes vagando na varanda enquanto somente as cuidadoras estavam dentro da casa, fazendo a limpeza ou a comida, algumas vezes com o portão de entrada para a cozinha trancado, sob o pretexto de que se aberto, os residentes mexeriam nas panelas.

Essa cuidadora, com sérios problemas de relacionamento com uma outra mais antiga, não tinha a intenção de permanecer na RT. Isso deixou claro o tamanho do desafio daquela residência, no que diz respeito à uma mudança de cultura das cuidadoras, principalmente em relação ao estabelecimento de uma rotina de tarefas e responsabilidades para os moradores, visando o desenvolvimento de mais autonomia. "Lá eles sentam na mesa e se servem. Aqui não, cada um recebe o prato na mão... parece que querem que continue assim, não querem agir diferente" (comparando a residência mais antiga e mista, com a mais recente).

Embora algumas cuidadoras tivessem dificuldade em conversar, raramente existiu recusa nas entrevistas durante as visitas. Mas foi notória a resistência das cuidadoras oficiais, responsáveis pela residência mais recente, em tentar qualquer tipo de mudança na rotina já estabelecida. Por isso, quando alguma cuidadora das outras residências em que os pacientes são mais autônomos aparecia para cobrir férias ou faltas, esta era recebida como 'invasora', ou seja, objeto estranho no local, aquele que perturba a ordem estabelecida. Também a sugestão do estabelecimento de uma rotina de tarefas para os moradores, como forma de reaprenderem a realizar tarefas simples como arrumar a cama, lavar a sua louça, e outras, deveria surgir de fora como uma meta, dada a dificuldade de ser assimilada pelas cuidadoras.

Uma das sugestões que as técnicas da CAPs levantaram, a partir do relato das cuidadoras foi o estabelecimento da tarefa conjunta de lavar o quintal, como forma de terem uma atividade diária onde todos interagissem, além da tarefa de arrumarem suas camas, como forma de ganharem autonomia e atividades dentro da casa.

O desenvolvimento de relações com os espaços da casa, bem como também as possibilidade de circulação na vizinhança e na cidade, iria ampliar a esfera das relações sociais do sujeito psicótico, lhe permitindo o acesso ao seu próprio eu. Ao estabelecer relações de cuidado com a casa, tarefas cotidianas, responsabilidades diárias, o sujeito amenizaria o sentido de 'hospital', e acenderia o sentido de 'casa' e do familiar e a lógica da internação começa a ser interrompida. 


\section{CONSIDERAÇÕES FINAIS}

O longo período de confinamento desses sujeitos em hospitais psiquiátricos e manicômios lhes fez perder a relação com os objetos considerados seus, pessoais, ou seja, a relação de propriedade e de pertencimento, bem como o copertencimento não se permitiu estabelecer. Na convivência diária, e no desenvolvimento de relações, práticas e atividades cotidianas nas Residências onde a autonomia é estimulada, os sujeitos conseguem iniciar o estabelecimento de relações de pertencimento com os objetos da casa. Igualmente desenvolvem sentido de lugar, e mesmo de pertencimento em relação ao espaço da casa, em relação uns aos outros e com os cuidadores.

A coexistência não basta para o desenvolvimento de laços de pertencimento, uma vez que ainda falta essa relação ser estimulada em termos de vizinhança. Os sujeitos pertencem à casa, mas não a vizinhança, uma vez que essa relação prescinde de maior circulação e do estabelecimento da coexistência com os vizinhos, o que ainda lhes é negado.

O estabelecimento de relações com os objetos e a casa se faz tão necessária quando o estabelecimento de relações com a vizinhança e com a cidade, para quer o sujeito psicótico se perceba no mundo, e se faz urgente a necessidade de se promover sua circulação pela vizinhança, e pelos lugares da cidade. Mesmo as relações que estes estabelecem entre si e com os cuidadores, só podem evoluir para fora da lógica hospitalar com a verdadeira significação dos espaços e esses ocupam social e fisicamente.

Não basta para o sujeito habitar um local que este possa chamar de casa, se os sentimentos de pertença a uma Residência não forem estimulados e permitidos, somente significando os espaços que os cercam, movendo-se e se permitindo nomear e sentir esses espaços para além de sua cama ou da varanda onde circulam, deitam, ou sentam. Se sentir em casa é se apropriar da casa, mas não apenas dela, é também circular na vizinhança e diferenciar a casa da rua, a casa do lugar de passeio, e a vizinhança dos sujeitos que moram na minha casa. A casa não apropriada e significada, não difere do hospital, e por isso as cuidadoras ainda são enfermeiras.

A ocupação dos espaços da casa pressupõe o estabelecimento de práticas cotidianas onde os sujeitos possam se relacionar com seus objetos, e desenvolver relações de pertença com suas roupas, escova de dentes, prato e outros objetos, mesmo que estes sejam de partilha coletiva, a casa é coletiva mas o lugar é meu antes de ser "nosso".

O sentimento de pertencimento, é anterior ao copertencimento, e precisa da coexistência para se estabelecer. Sem diferenciar os 'meus' do 'meu' e da vizinhança, o sujeito não é capaz de se sentir pertencente, muito menos de se perceber enquanto parte de um lugar.

O desenvolvimento da fala, da coordenação motora e da independência desses sujeitos somente será possível se forem estimulados a circular, a identificar os lugares da casa o diferenciando de outros, e de estabelecer com ela relações de convivência e de cuidados, esses cuidados também irão influenciar no estabelecimento dos cuidados de si, se eu tenho pertencimento à casa, o banheiro e o quarto me são diferentes, e sei que preciso ir ao banheiro quando preciso urinar, e que isso não devo fazer em qualquer lugar. 
Somente estimulando a apropriação por parte dos sujeitos dos espaços da casa, e dando a eles a possibilidade de conhecer novos espaços, que não o da casa, mas o da vizinhança, o da praia, e do passeio, terão condições de estabelecer com esse 'espaço da casa' uma relação de 'lugar'.

\section{REFERENCIAS}

AMARANTE, Paulo. Novos sujeitos, novos direitos: o debate em torno da reforma psiquiátrica. Cad. Saúde Pública, v.11, n.3, p.491-494,1995. 1996.

O homem e a serpente: outras histórias para a loucura e a psiquiatria. Rio de Janeiro: Ed. FIOCRUZ,

(Coord). Loucos pela vida: a trajetória da reforma psiquiátrica no Brasil. 2.ed. Rio de Janeiro: FIOCRUZ, 1998.

ARBEX, Daniela. Holocausto Brasileiro. São Paulo: Geração Editorial, 2013. 255 p.

BARROS, Sonia; BICHAFF, Regina. (Org.). Desafios para a desinstitucionalização: censo psicossocial dos moradores em hospitais psiquiátricos do Estado de São. São Paulo: FUNDAP, 2008.

BIRMAN, Joel. A Psiquiatria como discurso da moralidade. Rio de Janeiro: Graal, 1987.

BRAWLEY, Lisa. La pratique de la justice spatiale en crise. Justice Spatiale/Spatial Justice, Paris, n. 1, p. 9-34, sep. 2009. Disponível em: <http:/ / www.jssj.org>. Acesso em: 22 ago. 2015.

BRASIL. Ministério da Saúde. Legislação em saúde mental. Brasília, 2000a.

. Ministério as Saúde. Portaria GM n. 106, de 11 de fevereiro de 2000. Institui os Serviços Residenciais Terapêuticos no âmbito do Sistema Único de Saúde para o atendimento ao portador de transtornos mentais. Diário Oficial da União. Brasília, 2000b.

Ministério da Saúde. Lei n. 10.216, de 06 de abril de 2001. Brasília, 2001a. Disponível em: <http:// www.saude.gov.br>. Acesso em: 12 ago. 2015.

Ministério as Saúde. Secretaria de Atenção à Saúde. Departamento de Ações Programáticas e Estratégicas. Residências terapêuticas: que são. Para que servem? Brasília, 2004.

Ministério as Saúde. Secretaria de Atenção à Saúde. Departamento de Ações Programáticas e Estratégicas. Coordenação de Saúde Mental, Álcool e Drogas. Saúde Mental em Dados 7. Brasília, 2010. Disponível em: <http://portal.saude.gov.br/portal/arquivos/pdf/smdados.pdf>. Acesso em: 14 ago. 2015.

BRET, Bernard. L'universalisme rawlsien confronté à la diversité du reel. Justice Spatiale/Spatial Justice, Paris, n.1, set. 2009. Disponível em < http:/ / www.jssj.org/article/luniversalisme-rawlsien-confronte-a-ladiversite-du-reel> Acesso em: 15 ago. 2015.

CANGUILHEN, George. O Normal e o Patológico. Rio de Janeiro: Forense Universitária, 2009.

CASTEL, Robert: A Ordem Psiquiátrica: a Idade de Ouro do Alienismo. Rio de Janeiro: Graal, 1978.

CUNHA, Maria Clementina Pereira da. O espelho do mundo: Juquery, a história de um asilo. Rio de Janeiro: Paz e Terra, 1986.

FOUCAULT, Michel. A História da Loucura na Idade Clássica. São Paulo: Perspectiva, 1997.

. Doença mental e psicologia. Rio de Janeiro: Tempo Brasileiro, 1991.

GOULART, Maria Stella B. A construção da mudança nas instituições sociais: a Reforma Psiquiátrica. Pesquisas e Práticas Psicossociais, v.1, n.1, p. 1-19, 2006. Disponível em: <http://www.ufsj.edu.br/ portalrepositorio/File/revistalapip/A_Construcao_da_Mudanca_nas_Instituicoes_Sociais..._-MSB_ Goulart.pdf>. Acesso em: 15 ago. 2015. 
As raízes italianas do movimento antimanicomial. São Paulo: Casa do Psicólogo, 2007.

GOULART, Maria Stella B.; DURÃES, Flávio. A reforma e os hospitais psiquiátricos: histórias da desinstitucionalização. Psicologia \& Sociedade, v.22, n. 1, p. 112-120, 2010. Disponível em: <http://www. scielo.br/pdf/psoc/v22n1/v22n1a14> Acesso em: 16 ago. 2015.

LEFEBVRE, Henri. Le manifeste différentialiste. Paris: Gallimard, 1970.

O direito à cidade. 4. ed. São Paulo: Centauro, 2006.

A Vida cotidiana no mundo moderno. São Paulo: Ática, 1991.

Espaço e política. Belo Horizonte: Ed. UFMG, 2008.

MARCUSE, Peter. Spatial justice: derivative but causal of social injustice. Justice spatiale/ spatial justice, n. 1, p.1-6, sept. 2009. Disponível em: < https://www.jssj.org/wp-content/uploads/2012/12/JSSJ1-4en2. pdf>. Acesso em: 15 ago. 2015.

MASSEY, Doreen. Pelo Espaço: uma nova política da espacialidade. Rio de Janeiro: Bertrand Brasil, 2008.

MOREIRA, Maria Inês B. Se esta casa fosse minha: habitar e viver na cidade a partir de uma residência terapêutica. Vitória, 2007.186f. Tese (Doutorado em Psicologia) - Universidade Federal do Espírito Santo.

NIETZSCHE, Friedrich. Genealogia da moral: uma polêmica. Tradução, notas e posfácio Paulo César de Souza. São Paulo: Companhia das Letras, 2009.

PELBART, Peter Pál. A nau do tempo-rei: sete ensaios sobre o tempo da loucura. Rio de Janeiro: Imago, 1989.

RAWLS, John. Uma teoria da justiça. 2.ed. São Paulo: Martins Fontes, 2002.

Justiça como equidade: uma reformulação. São Paulo: Martins Fontes, 2003.

RIBEIRO NETO, Pedro Machado. Convivendo com residências terapêuticas: concepções sociais, processos identitários e relações intergrupais. Vitória, 2014.Tese (Doutorado em Psicologia) - Universidade Federal do Espírito Santo.

RIBEIRO NETO, Pedro Machado. Identidade social e desinstitucionalização: um estudo sobre uma localidade que recebe residências terapêuticas no Brasil. Saúde Sociedade, São Paulo, v.24, n.1, p.204-216, 2015.

RIMBAUD, Arthur. Poesia Completa. Organização e tradução de Ivo Barroso. Rio de Janeiro: Topbooks, 1994.

Uma Temporada no Inferno. Porto Alegre: L\&PM, 2001.

SOJA, La ville et la justice spatiale. Justice Spatiale/Spatial Justice, Paris, n. 1, p. 35-44, set. 2009. Disponível em: <http:/ / ww w.jssj.org.> Acesso em: 02 set. 2015.

TENÓRIO, Fernando. A reforma psiquiátrica brasileira da década de 1980 aos dias atuais: histórias e conceitos. História, Ciência, Saúde-Manguinhos, Rio de Janeiro, v. 9, n. 1, p. 25-59, jan./abr. 2002.

TUAN, Yi-Fu. Topofilia: um estudo da percepção, atitudes e valores do meio ambiente. São Paulo: Difel, 1980.

A Geografia Humanística. In: CHRISTOFOLETTI, A. (Org.). Perspectivas da Geografia. São Paulo: Difel, 1982. Cap. 7, p. 143-164.

Espaço e lugar: a perspectiva da experiência. São Paulo: Difel, 1983.

Human Goodness. Madison: The University of Wisconsin Press, 2008.

VEYNE, Paul. Foucault revoluciona a história. In: Como se escreve a história. 3.ed. Brasília: EUB, 1992. 